\title{
BRINGING HOME THE EUROPEAN CONVENTION ON HUMAN RIGHTS
}

\section{The Rt.Hon.The Lord Woolf *}

Early in its administration, the Government confirmed that Section 1 of the European Convention on Human Rights (Articles 2 to 12 and 14 to 18 and Protocol No 1 (Articles 1 to 3)) would be incorporated into domestic legislation. The Human Rights Bill, which will incorporate the Convention, is currently progressing through Parliament. This Bill will ensure that our courts apply the Convention rights in a way which reflects case law of the European Court of Human Rights at Strasbourg, enabling individuals to have access to rights here that at present they have to seek through the lengthy and expensive process of going to Strasbourg. The Convention rights will be available against public bodies only, and not against private bodies or individuals. The Human Rights Bill will bring the Convention home.

Experience in other parts of the Commonwealth suggests that incorporation of the Convention will change dramatically the landscape of the legal scene in Britain. It is true that, over the last ten years or so, some of the principles the Convention encapsulates have been entering our law by a process of osmosis. Many of the concepts enshrined in the Convention have therefore been given effect. Although we were not previously aware of it, all along these principles have been part of the common law! They were, so to speak, not foreign intruders but English princesses sleeping peacefully, waiting for the kiss of a judicial prince to bring them in turn to life when deciding a case.

However, the gradual process that has been taking place bears no relation to the impact which will result from making the Convention part of the law of this country. Incorporation will produce change on a scale which is perhaps without precedent. It will require the judiciary to adjust to a new situation. Even our becoming members of the European Community provides no true precedent. Lord Denning, my predecessor as Master of the Rolls and whose distinguished name this journal bears, described in a prophetic judgment the incoming tide

* The Master of the Rolls. 


\section{DENNING LAW JOURNAL}

making its way into the estuaries and up the rivers. 'By comparison to that gradual process, the enactment of the Human Rights Bill will be as though a tidal wave has transformed the legal landscape. It will affect every part of the law. If the experiences in New Zealand and Canada are typical, the effect on litigation will be immediate. We will see the effect in many criminal cases heard in magistrates' courts until legislation is reformed.

Instead of the slow and expensive route of taking proceedings to Strasbourg after domestic avenues of appeal have been exhausted, incorporation will give our courts the power to give effect to the Convention rights in the course of proceedings in this country as they arise. As in the common law, interpretation of the Convention articles will develop over time, but incorporation of the Convention will mean that the public and those who govern the public will be clear about what is the proper way to behave. Incorporation will give lawyers the opportunity to advance arguments they could not advance at present in our courts. This will mean that there will be a tendency for the law to develop as it has not developed before, bringing our law more into accord with that required by the Convention.

The Bill is going to change the focus of our law. Our system of public law is structured around duties. Public bodies are required to act in the spirit of the discretions given to them by Parliament. The Bill will shift the focus from the duties of public bodies to the rights of the individual.

After incorporation, individuals will have public rights in all areas of the law. The Lord Chancellor, in his recent Tom Sargent memorial lecture, said that "A citizen's right is asserted as a positive entitlement expressed in clear and principled terms." He suggested that the traditional common law approach to the protection of individual liberties offers little protection against a creeping erosion of freedom by a legislature willing to countenance infringement of liberty or simply blind to the effect of an otherwise well-intentioned piece of law. He drew attention to the 50 cases in which the European Court has found a violation of the Convention by the United Kingdom. The change to a rightsbased system will affect decisions made across the board - from criminal cases in magistrates' courts to applications for judicial review. The courts will be investigating whether citizens' rights have been infringed and, if so, whether infringement of those rights can be justified.

Personally I am pleased that the Bill restricts the courts' power to declaring that an Act of Parliament is inconsistent with a provision of the Convention but

' H.P. Bulmer Ltd. and another v. J.Bollinger S.A. and others [1974] 2 All E.R. 1226. 


\section{THE EUROPEAN CONVENTION ON HUMAN RIGHTS}

does not give the courts power to strike down or otherwise to affect the validity of an Act of Parliament. In this the Bill reflects the views of the vast majority of, if not possibly all, the senior judiciary. The judiciary regard what is proposed as being far more desirable than a Bill which enables the judiciary to strike down legislation. It is in accord with our constitutional traditions for legislation not to be struck down and for the courts to identify the inconsistency by a declaration. I anticipate there will be few cases where the courts will be unable to construe legislation in accordance with the Convention. But if they cannot, Parliament should decide how the situation should be rectified. A political decision of this sort is not an appropriate task for the courts. A declaration of incompatibility will trigger the ability to use a special fast-track procedure in Parliament to bring the law into line with the Convention.

My main concern about the Bill, which on the whole I warmly welcome, is its very narrow requirement as to standing. It is only a "victim" who can rely on the Convention before our courts. If we are not careful we could have a new divide which repeats the problems created by the distinction between the procedure for resolving public and private disputes. If there are two parties making the same complaint, one will be able to rely on both traditional judicial review grounds and the Convention and the other will only be able to rely on traditional judicial review grounds.

However, no matter how the Bill evolves during the process of Parliamentary scrutiny, when it comes into force it will be loyally applied by the courts. In applying the Bill, the courts will be adopting the role which they have clearly identified when hearing applications for judicial review. This role involves upholding the law. This role is fundamental to our constitution, and will continue even though the enactment of the Bill will undoubtedly increase the responsibility of the courts.

As I have said, the scale of the change will be large and wide-reaching. Incorporation of the Convention will change the process by which decisions are made. The courts will have to develop new skills. I have no doubt as to their ability to do so. However, it is imperative that the system is prepared properly. Judges need to be given the appropriate training; arrangements need to be put in place to manage the likely increase in litigation; appropriate avenues for appeal need to be devised. Judges and lawyers will need access to the necessary material, and to learn how to use it; to ensure they are familiar with decisions made by the European Commission and the European Court of Human Rights. Some law publishers are already making strides in widening the availability of these sources. It is impossible to say at this stage exactly what the relationship 


\section{DENNING LAW JOURNAL}

will be between these decisions and those made in our courts. What is certain, though, is that at the least they will be highly persuasive. We shall need to keep in step with decisions made in other Commonwealth jurisdictions whose constitutions include provisions similar to those of the Convention.

I believe that the spirit of the judiciary and practitioners will be to welcome the challenge that incorporation of the Convention presents. Such an approach will allow our judiciary and legal profession to make a proper contribution to European jurisprudence relating to human rights. That jurisprudence will be enriched through our involvement.

There are exciting times ahead for the law. 